УДК 811

DOI: 10.33184/YVDK-2021-04-30.6

Ю.В. Митченков (студ. СФ БашГУ, г. Стерлитамак), Е.А. Курочкина (cm. преп. СФ БашГУ, г. Стерлитамак)

\title{
ОСОБЕННОСТИ ПЕРЕВОДА АНГЛОЯЗЫЧНЫХ АББРЕВИАТУР В СФЕРЕ АСТРОНОМИИ
}

B статье рассматриваются особенности перевода англоязычных аббревиатур в сфере астрономии. Особую сложность представляют описательный способ перевода и создание нового сокращения, поскольку от переводчика требуется знание специиальной астрономической лексики и терминологии. Только в этом случае можно правильно передать смысл содержимого в аббревиатуре.

Ключевые слова: астрономия, аббревиатура, сокращение, перевод, транслитерачия, транскрипциия.

The article discusses the features of the translation of English abbreviations in the field of astronomy. The descriptive method of translation and the creation of a new abbreviation are especially difficult because the interpreter must know special astronomical vocabulary and terminology. Only in this case it is possible to correctly convey the meaning of the content in the abbreviation.

Key Words: astronomy, acronym, abbreviation, translation, transliteration, transcription.

Астрономия является одной из самых древних и интереснейших наук о Вселенной, истоки которой относятся к глубокой древности. Первоначально это учение о свойствах и движении небесных тел составляло единое целое с астрологией. Сегодня же под астрономией (от др.греч. «астер» - «звезда» и «номос» - «закон») понимается «наука о космических телах, образуемых ими системах и о Вселенной в целом» [URL: https://ozhegov.slovaronline.com]. 
Бурный научно-технический прогресс в XX веке повлиял на появление новых отраслей в современной астрономии, например: астрометрия, астрофизика, небесная механика, радиоастрономия, гамма-астрономия, космохимия, звездная астрономия и т.д.

Развитие астрономии как самостоятельной науки и появление большого количества новых отраслей знаний способствовали появлению соответствующей терминологии в данной сфере.

Одним из самых востребованных и продуктивных способов терминообразования в области астрономии на сегодняшний день является аббревиация, которая используется не только в русском и английском языках, но и во всех европейских. На это повлияли ускоренный ритм жизни и как следствие экономия языковых усилий. Однако вместе с этим возникла проблема поиска наиболее эффективных способов и путей перевода аббревиатур.

В толковом словаре С. А. Трушкина под аббревиатурой (от лат. brevis - краткий) понимается «существительное, образованное из усечённых отрезков слов, из таких же отрезков в сочетании с целым словом, а также из начальных звуков слов или названий их начальных букв, сложносокращённое слово» [URL: https://ozhegov.slovaronline.com].

В толковом словаре Т. Ф. Ефремовой под аббревиатурой понимается «условное сокращение в буквенном и нотном письме»

[URL: https://www.efremova.info/word/abbreviatura.html\#.YFS6SasmxPY].

Выделяют следующие типы научно-технических аббревиатур и сокращений, встречающиеся как в научных текстах, так и в газетно-информационных публикациях [URL: https://scienceforum.ru/2014/article/2014001856].

- инициальные (или буквенные) аббревиатуры, которые состоят из первых букв или звуков слов, например: BST (British Summer Time) - Британское летнее время;

- акронимы, которые также состоят из первых букв, но будут читаться как обычное слово, например: UFO (unidentified flying object) НЛО (неопознанный летающий объект);

- слоговые (или усеченные) аббревиатуры. В англоязычных специальных текстах часто встречаются такие 
слова, например: HIP - (каталог) HIPPARCOS, каталог данных, произведенных Hipparcos;

- комбинация сокращения с целым словом, где сам термин заменяется литерой, а более распространенное слово пишется цеиком, например: G-catalog - Giclas, a catalog of nearby stars (Каталог Глизе);

- смешанные типы аббревиатур, где можно использовать несколько видов аббревиатур совместно, например: инициальнобуквенный и слогово-усеченный тип: OSIRIS-REx (Origins Spectral Interpretation Resource Identification Security Regolith Explorer) - американская автоматическая межпланетная станщия, предназначенная для доставки образцов грунта с астероида Бенну.

Еще одной особенностью астрономических терминоваббревиатур является сочетание литер и цифр. Данные типы сокращений используются для обозначения спецификации или индексации, например: 2MASS (Two-Micron All Sky Survey) программа наблюдений, предполагающая обзор всего неба в ближнем ИК диапазоне.

Лингвисты выделяют следующие способы перевода англоязычных аббревиатур в сфере астрономии на русский язык [URL: https://core.ac.uk/download/pdf/227033468.pdf]:

1. перевод английского сокращения с помощью эквивалентного русского сокращения, например: $A D$ (accretion disk) - АД (аккреционныий диск); ANG (active galactic nucleus) АЯГ (активное ядро галактики); АO (adaptive optics) - AO (адаптивная оптика); LBY (large binocular telescope) - ББТ (большой бинокулярный телескоn); NS (neutron star) - H3 (нейтронная звезда); N (nova) - H3 (новая звезда); BH (black hole) - ЧД (черная дыра); NEO (near-earth-object) - OЗО (околоземный объект); NEA (near-eartg-asteroid) - ОЗА (околоземный астероид) [URL: http://www.astronet.ru/db/dict/].

В данном случае при переводе и поиске соответствующего русского эквивалента переводчик использует определённую научную литературу, где и находит максимально приближенное по своему смыслу и значению понятие.

2. Полное заимствования английского сокращения (калькирование) предполагает освоение слова языкомреципиентом целиком со своим произношением, написанием и 
значением. Данный метод применятся при заимствовании буквенно-цифровых аббревиатур, которые входят в состав индексации или спецификаций и т. д. Так например, данный способ перевода применяется для передачи каталожного номера каждого летающего космического объекта, находящегося на орбите и зарегистрированного в COSPAR: STS-133 - 39-й космический полёт МТКК «Дискавери» по программе «Спейс шаттл»; 1997-061А - номер полета автоматической межпланетной станции Касси́ни-Гю́йгенс. К данному виду сокращений также могут быть причислены название различных телескопов Паломарской обсерватории (Р48, Р60, Р200), где цифрами обозначаются дюймы [URL: https://scienceforum.ru/2014/article/2014001856].

3. Метод транслитерации предполагает передачу буквенного состава аббревиатуры, например: NASA (national aeronautics and space administration) - американское агентство по изучению аэронавтики и космического пространства НАСА; FORTRAN (formula translation) - процедурный алгоритмический язык «Фортран»; TACAN (tactical air navigation) - тактическая навигационная система «Такан»; ILS (instrument landing system) - система инструментальной посадки ИЛС [URL: http://www.astronet.ru/db/dict/].

Однако данный метод не применяется, если в языкереципиенте уже есть схожее по звучанию слово и обладающее собственным смыслом, например: COSMOS (cosmic evolution survey) - программа изучений и наблюдения космического пространства и его эволючии; LINER (low-ionization nuclear eтission-line) - тип галактического ядра, который определяется его спектральной линией излучения; САSCA - (организация) Канадское астрономическое общество; ATLAS (Australia telescope large area surbey) - программа глубокого наблюдения звездного неба методам радиоастрономии в рамках 7 квадратных градусов неба [URL: http://www.astronet.ru/db/dict/].

4. Метод транскрипции предполагает передачу произношения английской аббревиатуры, а не ее буквенный состав английского сокращения. Как правило, данный метод используют при переводе названий астрономических приборов и инструментов, применяемых за наблюдением небесных тел, например: EAGLE (elevation angle guidance landing equipment) - 
глиссадный посадочный радиомаяк «Игл» с управлением угла места; APHAZ (aircraft proximity hazards assessment panel) приборы оиенки возможного риска АФАЗ [URL: https://scienceforum.ru/2014/article/2014001856].

5. Описательный способ перевода английского сокращения, который используется, когда в русском языке нет соответствующих эквивалентов. Этот способ передачи английского сокращения должен полностью определять техническую сущность корня, основные характеристики явления или особенности применения того или иного предмета, например: CSE - (celestial object) околозвездная оболочка, примерно сферическая планетарная туманность сформированный из плотного звездного ветра, если он отсутствовал до образования звездыр; OPEN (origins of plasma in Earth's neighbourhood) источники плазмы в околоземном пространстве; ТМС (Taurus Molecular Cloud) - молекулярное облако в созвездии Тельца; SagDIG (Sagittarius Dwarf Irregular Galaxy) - карликовая неправильная галактика в Стрельие; EC (Embedded Cluster) звездное скопление, которое частично или полностью погружено в межзвездный газ или пыль; HB (Horizontal branch) - небесный объект, тип эволючионировавшей красной гигантской звезды , в которой гелий сгорает в ядре, а водород сгорает в оболочке вокруг ядра; PegDIG (Pegasus Dwarf Irregular Galaxy) карликовая неправильная галактика в Пегасе [URL: https://scienceforum.ru/2014/article/2014001856].

6. Метод образования новой аббревиатуры в языкереципиенте предполагает совместную работу переводчика и специалистов в соответствующей области и новое сокращение должно быть одобрено учеными, например: SNR (supernova remnant) - остаток сверхновой. Существующая в русском астрономическом дискурсе аббревиатура сверхновой (CH) позволяет образовать краткое обозначение и для такого редкого и узкоспециализированного явления, как остаток сверхновой OCH; SETI (search for extraterrestrial intelligence) - поиск разумной жизни (ПРЖ).

Как видно из примеров, аббревиатуры и сокращения довольно распространены в астрономическом дискурсе. Основная цель их использования - придание лаконичности и ясности научной документации. Они позволяют увеличить скорость 
чтения и помогают эффективнее презентовать информацию в научном тексте по астрономии.

Однако из-за быстрых темпов создания новых терминоваббревиатур в сфере астрономии, возникает проблема их адекватного и корректного перевода. Наибольшие трудности вызывают описательный способ перевода и создание новых аббревиатур и сокращений, поскольку от переводчика требуется наличие определённых знаний в данной научной сфере, владение специальной и узкоспециальной лексикой и терминологией и, кроме того, не редко предполагается совместная деятельность специалиста и переводчика.

\section{ЛИТЕРАТУРА}

1. Англо-Русско-Английский Астрономический Словарь. URL: http://www.astronet.ru/db/dict/ (дата обращения: 16.03.2021).

2. Ефремова Т. Ф. Новый словарь русского языка. Толковословообразовательный [Электронный ресурс]. - М.: Русский язык, 2000.

URL:

https://www.efremova.info/word/abbreviatura.html\#.YFS6Sasmx PY (дата обращения: 16.03.2021).

3. Трушкин С. А. Толковый словарь русского языка [Электронный pecypc]. - М.: «Азь», 1992. URL: https://ozhegov.slovaronline.com (дата обращения: 16.03.2021).

4. Тяжлова Д.А. Структурно-семантические и функциональные особенности аббревиатур в английской военной лексике. [Электронный pecypc].

URL: https://core.ac.uk/download/pdf/227033468.pdf (дата обращения: 24.03.2021).

5. Шатохин М.Д. Особенности перевода аббревиатур в научнотехнических текстах / М.Д. Шатохин, Л.В. Смолина. Студенческий научный форум - 2014: материалы VI Международной студенческой научной конференции. [Электронный pecypc].

URL: https://scienceforum.ru/2014/article/2014001856 (дата обращения: 26.03.2021).

6. List of astronomy acronyms [Электронный ресурc]. URL: https://scienceforum.ru/2014/article/2014001856 (дата обращения: 14.03.2021).

(C) Митченков Ю.В., Курочкина Е.А., 2021 г. 